\title{
All Optical WDM-to-OTDM Conversion at Reduced Channel Spacing using HNLF
}

\author{
Abhishek Sharma \\ Student \\ Department of ECE \\ BGIET, Sangrur
}

\author{
Sushil Kakkar \\ Assistant Professor \\ Department of ECE \\ BGIET, Sangrur
}

\begin{abstract}
With the growing requirement for advanced speeds and better capacity brought about by speedy data expansion on the Internet, Optical time division multiplexing attracted much attention for its high speed operations and ability to overcome the electronic bottleneck problems. In this article, $4 \times 10 \mathrm{~Gb} / \mathrm{s}$ WDM/OTDM conversion using super continuum(SC) generation at $100 \mathrm{Ghz}$ is proposed for $12 \mathrm{Km}, 24 \mathrm{Km}$ and $36 \mathrm{Km}$ using SPWRM( Symmetrical pulse width reduction module). HNLF based multiplexing eliminate the requirement of extra pump sources and provide cost effective solution.FWM (four wave mixing) demultiplexing using SOA(semiconductor optical amplifiers) is achieved for all the 4 channels with acceptable limits of BER $=10^{-9}$ at $24 \mathrm{Km}$.
\end{abstract}

\section{Keywords}

Pulse width reduction, four wave mixing, supercontinuum, semiconductor optical amplifier, wavelength division multiplexing

\section{INTRODUCTION}

Wavelength division multiplexing (WDM) and Optical time division multiplexing are the promising technologies characterized by capacity of high transmission in optical communication systems possess their own benefits [1].In current scenario, it is quite obvious expand the reach of optical systems and to enhance all-optical processing in order to overcome bottleneck problems which replace conventional E/O conversion with electronic switches in high speed OTDM networks.WDM to OTDM systems to provide all-optical conversion, such solution becomes a significant move for providing system operations at photonic gateways [2].Basics of WDM/OTDM system is to aggregate or transmultiplex lower data rate tributaries operated at dissimilar frequencies for the realization of high speed core networks [3].Till now, lot of work has been reported for WDM/OTDM conversion by using different non linear mediums such as electroabsorption modulator (EAM), semiconductor optical amplifiers(SOA) and MZI-SOA [4].However the limitation of modulators and amplifiers is the restricted frequency response. Highly non linear fibers provide efficient solution and attracted much attention for realization of optical signal processing. Another approach for OTDM/WDM conversion using four wave mixing and XPM (cross phase modulation) [5].However additional pumps sources are required to realize conversion based on Raman compression [6], non linear optical loop mirror (NOLM).Super continuum generation using HNLF has been reported experimentally for $4 \times 10 \mathrm{~Gb} / \mathrm{s}$ WDM/OTDM conversion at $200 \mathrm{GHz}$ spacing. Advantage of using SC generation is a cost effective solution to eliminate the requirement of extra pump sources.

In this article, We demonstrated a simulation setup of WDM/OTDM conversion using SC generation at $100 \mathrm{GHz}$ channel spacing for long distance transmission employing symmetrical pulse reduction technique. Conversion of $4 \times 10$ $\mathrm{Gb} / \mathrm{s} \mathrm{WDM}$ to $40 \mathrm{~Gb} / \mathrm{s}$ OTDM has been realized at less channel spacing with time interleaving provided by delay blocks and isolation of different wavelengths achieved with $4 \times 4$ array waveguide grating in demultiplexed mode.FWM demultiplexing is used for reception of each channel incorporating semiconductor optical amplifier (SOA).Therefore, a bandwidth efficient all-optical WDM/OTDM system with the cost effective solution measuring $\mathrm{BER}<10^{-9}$ for $24 \mathrm{Km}$ has been proposed.

\section{FUNCTIONING THEORY}

$\mathrm{M}$ wavelengths $\lambda 1, \lambda 2 \ldots . \lambda \mathrm{M}$ are generated using MZM (mech-zhender modulator) and followed by EAM (electroabsorption modulator) for generating RZ line coding converted with a drive from sine generator synchronized to NRZ in order to realize ultra short pulse. Transmitted data from $\mathrm{M}$ channels with $\mathrm{D}$ rate is calculated using $\mathrm{B}=\mathrm{M} \times \mathrm{D}$ for total data rate.AWG is operated in demultiplexing mode for routing of each wavelength to different output port followed by time delay module. Each channel delayed by $\Delta t$ for time interleaving and fed to HNLF for SPM (Self phase modulation).SPM is calculated as [7]

$$
\Delta \omega=\frac{\mathrm{w}}{\mathrm{c}} \mathrm{n} 2 \mathrm{z} \frac{\mathrm{Ic}}{\tau}
$$

SPM cause spectrum broadening in HNLF and overlapped spectrum achieved with common wavelength referred as $\lambda \mathrm{c}$. Optical filter is used to select the $\lambda \mathrm{c}$ from the broader and overlapped spectrum. Symmetrical pulse reduction technique is used with $\mathrm{L} / 2 \mathrm{Km}$ length of SMF before and after DCF of length $\mathrm{L} \mathrm{Km}$ in order to mitigate the effects of pulse broadening.

\section{SIMULATION SETUP}

Figure.1(a). Represents the Transmitter setup for $40 \mathrm{~Gb} / \mathrm{s}$ WDM/OTDM system at $100 \mathrm{GHz}$ channel spacing employing symmetrical pulse width reduction technique. A continuous wave laser array is used to transmit four optical reference signals starting from $1557.35 \mathrm{~nm}$ to $1559.79 \mathrm{~nm}$ with $0.8 \mathrm{~nm}$ channel spacing followed by a mech-zhender modulator driven by NRZ line coder from PRBS of order 27-1 biased at $10 \mathrm{~Gb} / \mathrm{s}$.EAM converts NRZ to RZ for generating a ultra short pulse which synchronized with $10 \mathrm{GHz}$ sine pulse generator. $4 \times 4$ AWG is used in demux mode for routing of different wavelengths to different output ports. Each separated wavelength temporarily interleaved or shifted by $0 \mathrm{~ns}, 0.025 \mathrm{~ns}$, $0.05 \mathrm{~ns}, 0.075 \mathrm{~ns}$ and amplified by EDFA then fed to HNLF for SC generation as shown in Fig.1 (b). Specification of HNLF are given in Table.1.Overlapped spectrum wavelength $\lambda \mathrm{c}$ at $1558.88 \mathrm{~nm}$ is filtered out by using optical Bessel filter of bandwidth $0.3 \mathrm{~nm}$.Power booster EDFA with $10 \mathrm{~dB}$ gain incorporated after optical filter and converted signal 
transmitted over symmetrical pulse width reduction module consisting of single mode fiber(SMF), EDFA and DCF. Specification of PWR module is given in Table.2.Figure.1(c). shows the Demultiplexing of each channel at receiver part using SOA of 0.3 confinement factor.BER vizualizer evaluates the system performance in terms of eye opening, power penalty, eye closer penalty and OSNR.

Table I- Specification of HNLF

\begin{tabular}{cc}
\hline Quantity & Values \\
\hline HNLF Length & $2 \mathrm{Km}$ \\
$2^{\text {nd }}$ Order Dispersion & $-2.2 \mathrm{ps} / \mathrm{nm} / \mathrm{Km}$ \\
$3^{\text {rd }}$ Order Dispersion & $0.032 \mathrm{ps} / \mathrm{nm}^{2} / \mathrm{Km}$ \\
$\mathrm{A}_{\text {eff }}$ & $11 \mathrm{um}^{2}$ \\
Attenuation & $0.55 \mathrm{~dB} / \mathrm{Km}$ \\
\hline \hline
\end{tabular}

TABLE II- SPWR module specifications

\begin{tabular}{cc}
\hline Parameters & Values \\
\hline SMF & $10 \mathrm{Km} /$ each Loop \\
DCF & $2 \mathrm{Km} /$ each Loop \\
Attenuation $_{\mathrm{SMF}}$ & $0.2 \mathrm{~dB} / \mathrm{Km}$ \\
Attenuation $_{\mathrm{DCF}}$ & $0.5 \mathrm{~dB} / \mathrm{Km}$
\end{tabular}

$\begin{array}{cc}\text { Aeff }_{\text {SMF }} & 72 \mathrm{um}^{2} \\ \text { Aeff }_{\text {DCF }} & 22 \mathrm{um}^{2} \\ \text { Dispersion }_{\text {SMF }} & 17 \mathrm{ps} / \mathrm{nm} / \mathrm{Km} \\ \text { Dispersion }_{\text {DCF }} & -85 \mathrm{ps} / \mathrm{nm} / \mathrm{Km}\end{array}$

\section{RESULTS \&DISCUSSION}

Figure.2 (a) represents the four different wavelengths each biased with $10 \mathrm{~Gb} / \mathrm{s}$ data signal after MZM. Signal broadening spectrum of all the four channels after SC generation due to SPM shown in Fig.1 (b). Overlapped spectra achieved after $\mathrm{HNLF}$ and $\lambda \mathrm{c}$ is filtered out using optical Bessel filter as 40 $\mathrm{Gb} / \mathrm{s}$ OTDM signal represented in Fig.2(c).OTDM signal transmitted over optical fiber transmission module consisting of SMF of $10 \mathrm{Km}$ and DCF of $2 \mathrm{Km}$ followed by EDFA with $5 \mathrm{~dB}$ gain after each SMF and DCF in order to compensate attenuation effects. Symmetrical pulse width reduction arrangements are used and system performance investigated for $12 \mathrm{Km}, 24 \mathrm{Km}$ and $36 \mathrm{Km}$.Figure.3. shows the graphical representation of all demultiplexed channels at different distance in terms of Q-factor. Also BER performance of all the channels with respect to received power has evaluated as shown in Fig.4.System works successfully for $12 \mathrm{Km}$ of link distance with BER value 10-11 and maximum achievable distance evaluated at BER $10-9$ for $24 \mathrm{Km}$. Power penalty is observed more at channel 4 as compared to other demultiplexed channels.

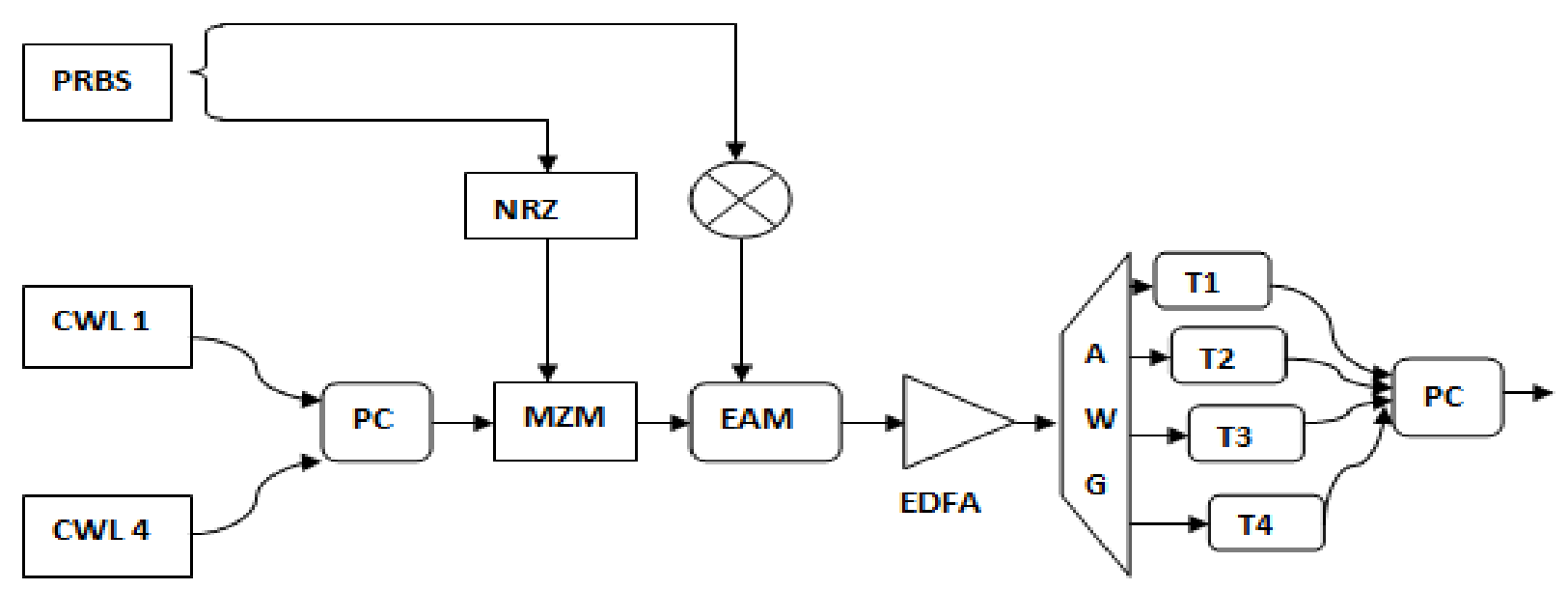

Fig 1(a): Transmitter setup for $40 \mathrm{~Gb} / \mathrm{s} \mathrm{WDM/OTDM} \mathrm{system} \mathrm{at} \mathrm{100GHz}$

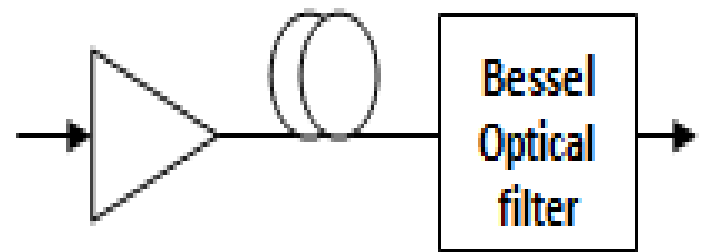

\section{EDFA HNLF}

Fig.1(b).Super continuum Generation 


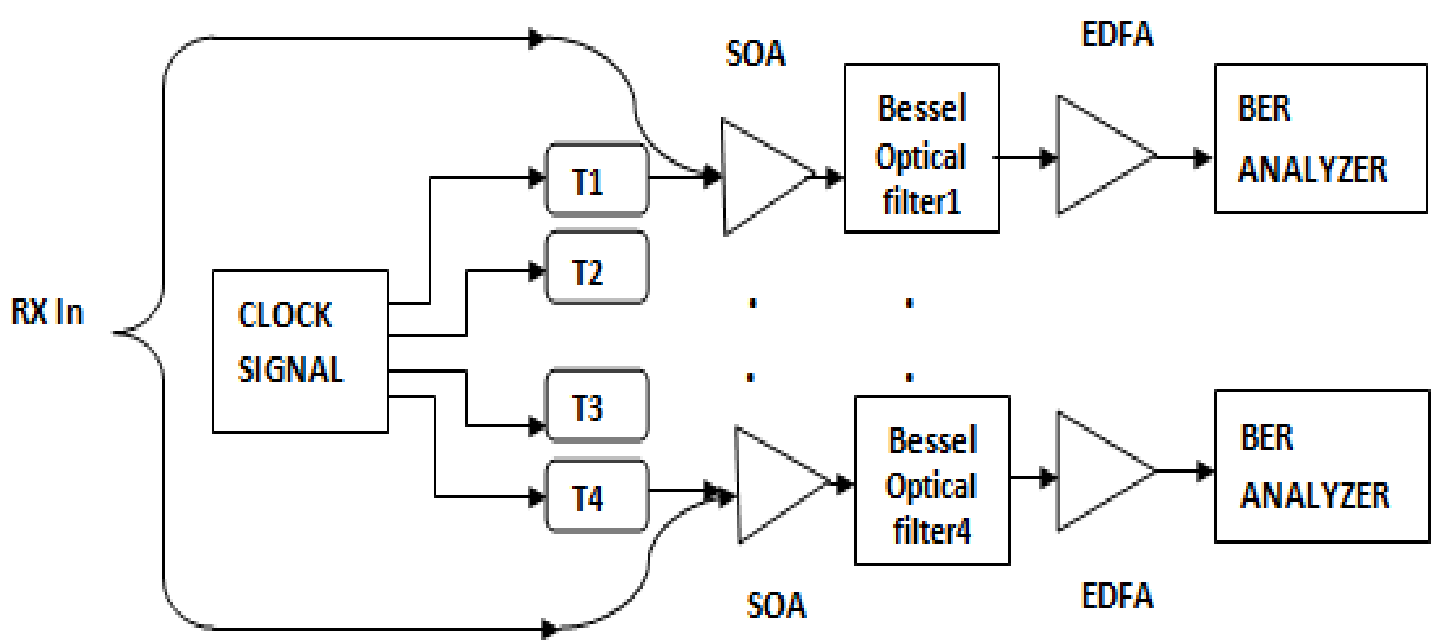

Fig.1(c).FWM based demultiplexing using SOA

宣 Optical Spectrum Analyzer_12

DbI Click On Objects to open properties. Move Objects with Mouse Drag

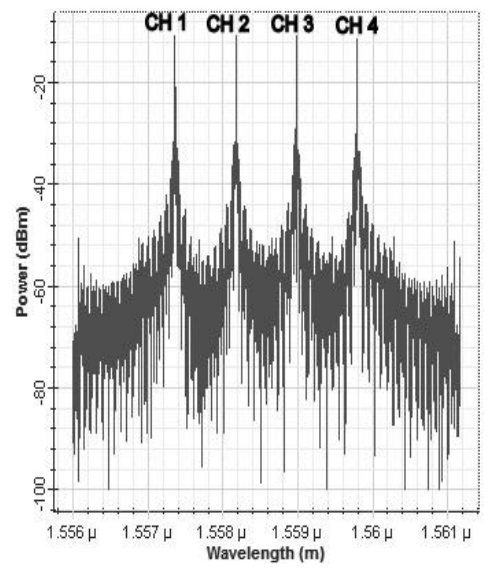

(a)

曷 Optical Spectrum Analyzer Dbl Click On Objects to open properties. Move Objects with Mouse Drag

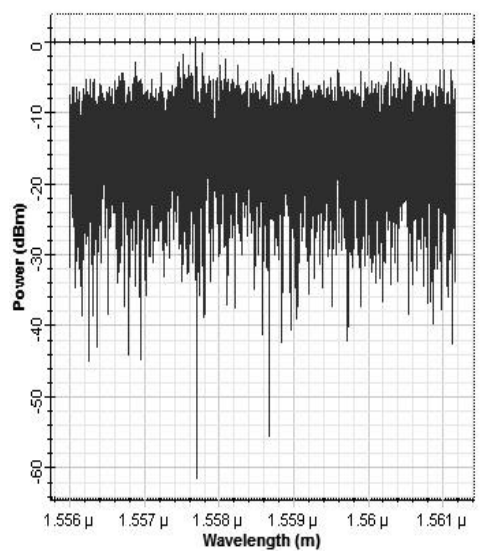

(b)

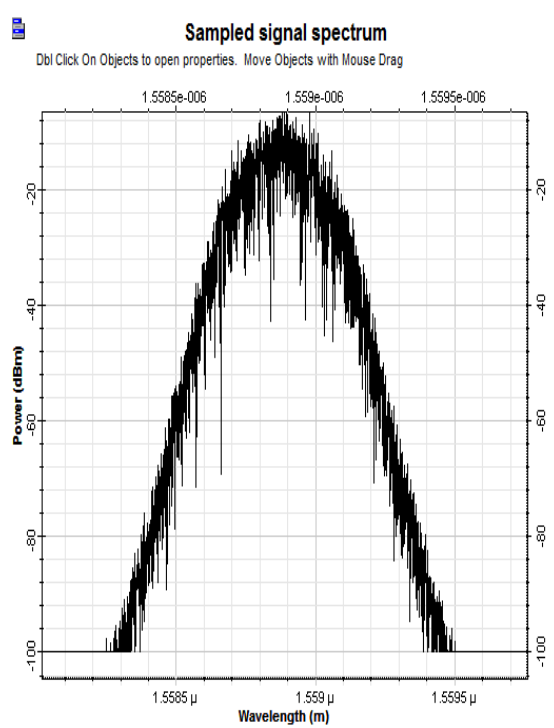

(c)

Fig.2.Optical power spectrum of (a) $4 \times 10 \mathrm{~Gb} / \mathrm{s}$ WDM channels (b) After SC generation (c) Filtered $\lambda c$

In this work, demonstration of WDM to OTDM conversion at $100 \mathrm{GHz}$ channel spacing and converted OTDM signal successfully transmitted over $24 \mathrm{Km}$ using SPWRM is done. More system capacity may be achieved by using more application specific highly nonlinear fiber in the system as HNLF face challenges to work on higher bit rates due to high non linear coefficient. 


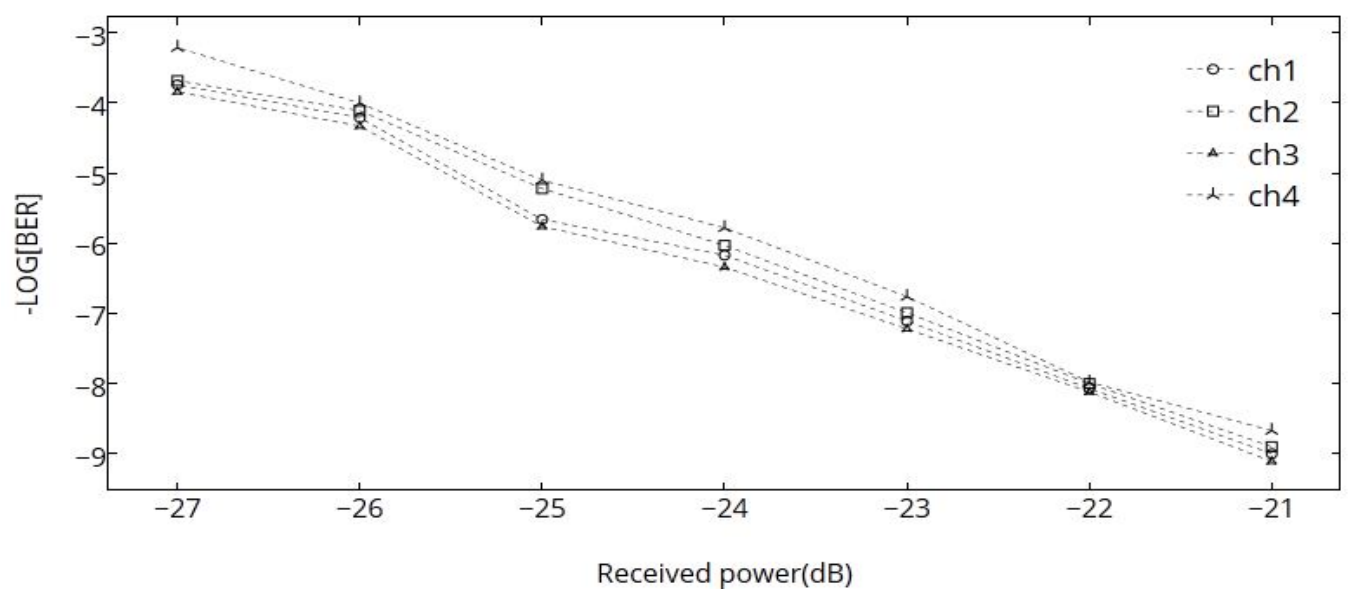

Fig.3.BER measurements for demultiplexed channels

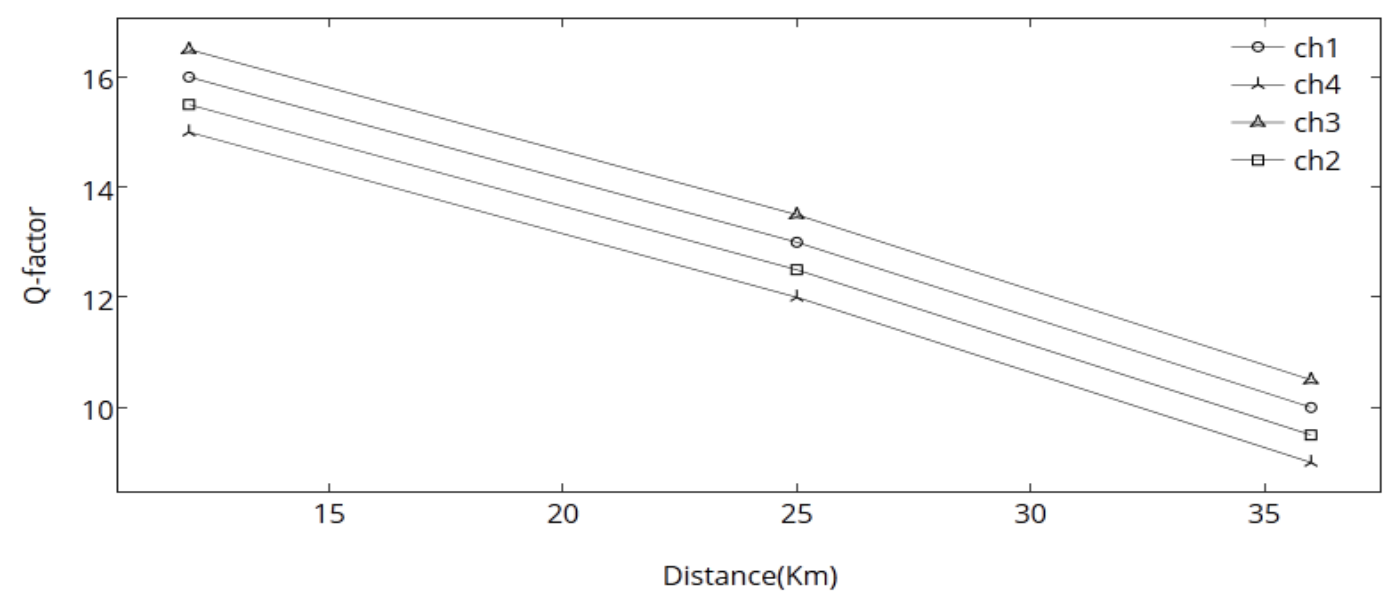

Fig.4.Evaluation of demultiplexed channels at different distance

\section{CONCLUSIONS}

All optical 4x10 Gb/s WDM to OTDM conversion at $100 \mathrm{GHz}$ has successfully realized in this work using super continuum generation base on SC multiplexing by incorporating HNLF. $40 \mathrm{~Gb} / \mathrm{s}$ OTDM signal transmitted over $24 \mathrm{Km}$ link of fiber using SPWRM with acceptable BER of 10-9.Demltiplexing of four different channels realized with semiconductor optical amplifiers(SOAs) using Four wave mixing(FWM). By the use of Supercontinuum generation, the need to use additional pumps at the time of conversion has been eliminated. The results received are at par in terms of quality and trends and are also verified with spectra where conversion can be evidently seen.

\section{REFERENCES}

[1] T. Ohara et al., "Over-1000-channel ultradense WDM transmission with supercontinuum multicarrier source," J. Lightw. Technol., vol. 24, no. 6, pp. 2311-2317, Jun. 2006 .

[2] M. Nakazawa, T. Yamamoto, and K. R. Tamura, "1.28 $\mathrm{Tb} / \mathrm{s}-70 \mathrm{~km}$ OTDM transmission using third- and fourthorder simultaneous dispersion compensation with a phase modulator," Electron. Lett., vol. 36, no. 24, pp. 20272029, Nov. 2000.
[3] H. Sotobayashi, W. Chujo, and K.-I. Kitayama, "Photonic gateway: TDM-to-WDM-to-TDM conversion and reconversion at $40 \mathrm{Gbit} / \mathrm{s}(4$ channels $\times 10 \mathrm{Gbits} / \mathrm{s})$," J. Opt. Soc. Amer. B, vol. 19, no. 11, pp. 2810-2816, Nov. 2002.

[4] V. Polo, J. Prat, J. J. Olmos, I. T. Monroy, and A. M. Koonen, "Alloptical FSK-WDM to intensity modulationOTDM transmultiplexing for access passive optical networks," J. Opt. Netw., vol. 5, no. 10, pp. 739-746, Oct. 2006.

[5] B.-E. Olsson and D. J. Blumenthal, "WDM to OTDM multiplexing using an ultrafast all-optical wavelength converter," IEEE Photon. Technol. Lett., vol. 13, no. 9, pp. 1005-1007, Sep. 2001.

[6] Q. Nguyen-The, H. N. Tan, M. Matsuura, and N. Kishi, "All-optical WDM-to-OTDM conversion using a multiwavelength picosecond pulse generation in Raman compression," IEEE Photon. Technol. Lett., vol. 24, no. 24, pp. 2235-2238, Dec. 15, 2012.

[7] P. Agrawal, Nonlinear Fiber Optics. New York, NY, USA: Academic, 1995. 